\title{
Is transarterial embolization a valuable treatment option for spontaneous rupture of hepatocellular carcinoma: experience from a tertiary care hospital of South-Asia
}

\author{
Amna Subhan Butt ${ }^{1}$, Saeed Hamid ${ }^{1}$, Nazish Butt $^{1}$, Fatima Sharif ${ }^{2}$, Tanveer UI Haq ${ }^{3}$, Wasim Jafri $^{1}$ \\ ${ }^{1}$ Section of Gastroenterology, Department of Medicine, The Aga Khan University, Karachi 74800, Pakistan \\ ${ }^{2}$ The Aga Khan University, Karachi 74800, Pakistan \\ ${ }^{3}$ Department of Radiology, The Aga Khan University, Karachi 74800, Pakistan
}

Correspondence to: Dr. Amna Subhan Butt, Section of Gastroenterology, Department of Medicine, The Aga Khan University Hospital, Stadium Road, Karachi 74800, Pakistan. E-mail: amna.subhan@aku.edu

How to cite this article: Butt AS, Hamid S, Butt N, Sharif F, Haq TU, Jafri W. Is transarterial embolization a valuable treatment option for spontaneous rupture of hepatocellular carcinoma: experience from a tertiary care hospital of South-Asia. Hepatoma Res 2016;2:279-86.

Article history:

Received: 04-04-2016

Accepted: 02-08-2016

Published: 21-10-2016

\section{Key words:}

Ruptured hepatocellular carcinoma, transarterial embolization, Pakistan

\begin{abstract}
Aim: Transarterial embolization (TAE) has been found beneficial in treatment of ruptured Hepatocellular carcinoma (HCC) in earlier studies. So far no data is available from Pakistan. The aim of this study was to evaluate clinicopathological characteristics, outcomes of patients presented with spontaneously ruptured, unresectable HCC treated with or without TAE and to evaluate the factors associated with 30-day mortality. Methods: This was a cross sectional study. Patients $\geq 18$ years old, presented with spontaneous rupture of unresectable HCC, were evaluated. The outcome measures were control of bleeding, in-hospital mortality, 30day mortality and factors associated with 30-days mortality. Results: Out of 850 patients, 24 patients were diagnosed with spontaneously ruptured HCC. Mean age was $58.29 \pm 15.26$ years. A total of $11(45.8 \%)$ patients were treated conservatively and $13(54.2 \%)$ underwent TAE. Control of bleeding due to ruptured HCC was significantly higher for those treated via TAE as compared to those who were treated conservatively $(92.3 \%$ vs. $36.4 \%, P=0.008)$. Overall median duration for which the patients remained alive after HCC rupture was longer for TAE group (39 days vs. 5 days, $P=0.03)$. In-hospital mortality $(30.8 \% v s .72 .7 \%, P=0.04)$ and 30 -day mortality was also lower in TAE group $(38.5 \%$ vs. $90.9 \%, P=0.01)$. Those who underwent TAE had lower risk of mortality then conservative group [odds ratio (OR) 0.25 , $95 \%$ confidence interval $(\mathrm{CI}) 0.07-0.90, P=0.03)$. Failure to control bleeding was associated with higher 30-day mortality (OR 2.14, 95\% CI 1.24-3.68, $P=0.009)$. Conclusion: Ruptured $\mathrm{HCC}$ is a life threatening complication requiring early diagnosis and treatment. TAE is an effective and well-tolerated treatment in the management of ruptured HCC.
\end{abstract}




\section{INTRODUCTION}

Hepatocellular carcinoma (HCC) is the fifth most common cancer and the third leading cause of cancer related mortality worldwide. ${ }^{[1]}$ Relatively higher incidence rates have been reported from South Eastern Asia and sub-Saharan Africa. ${ }^{[2]}$ The incidence rate of HCC in Pakistan is equivalent to 2.5 per 100,000 persons per year which is higher than the Sub-continent and Western countries. ${ }^{[3]}$ Moreover, hepatitis $C$ and $B$ virus infection have been reported to be the major attributable factors responsible for HCC in Pakistan. ${ }^{[4]}$

While, most of the patients remain asymptomatic, $\mathrm{HCC}$ can manifest with right hypochondrial pain, weight loss, new onset jaundice and ascites. ${ }^{[5]}$ Hemoperitoneum caused by spontaneous rupture of HCC is a rare but fatal complication associated with mortality ranging between $25-75 \%{ }^{[6,7]}$ The incidence of spontaneous rupture of HCC ranges 3-15\% in South-East Asian countries, which is higher as compared to the reported incidence of $<3 \%$ in Western countries. ${ }^{[6,8,9]}$ Spontaneous rupture of $\mathrm{HCC}$ is associated with poor liver functional reserve, advanced stage of tumor and high mortality rates ranging $32-62 \%$ as seen in various studies. $^{[10-12]}$

It is not only difficult to anticipate the HCC rupture; there are few therapeutic options available to treat such patients. The treatment modalities that have been employed include emergency liver resection in case of preserved liver function and resectable tumor, transarterial embolization (TAE) or transarterial chemoembolization (TACE) in case of advanced disease. ${ }^{[12,13]}$ TAE has been found beneficial in the treatment of ruptured HCC in earlier studies by allowing control of bleeding and the selection of suitable patients for later liver resection. However, the utility of available treatment options is limited due to the patient's clinical condition and disease stage.$^{[9,13,14]}$ Moreover, most of the data available consists of studies with nonhomogenous study population with variable disease stages, small sample size and limited results related to prognostic factors. No data is available from Pakistan so far.

Hence, in the current study, we report five years' experience with patients who presented with spontaneous rupture of unresectable HCC treated with or without TAE. The aim is to evaluate clinicopathological characteristics and outcomes of patients presenting with spontaneously ruptured, unresectable HCC treated with or without TAE and to evaluate the factors associated with 30-day mortality.

\section{METHODS}

\section{Study population and duration}

This was a retrospective cross sectional study. Patients $\geq 18$ years of age, already diagnosed to have $\mathrm{HCC}$ and admitted to Gastroenterology ward of Aga Khan University Hospital (AKUH) during 2006-2015 were identified from our data base by using ICD code 1550 . AKUH is a 563 bed, large tertiary care hospital in the metropolitan city of Karachi with a population of 18 million. ${ }^{[15]}$ The medical record coders at AKUH assign numerical codes for diseases and procedures to all records in accordance with standards outlined in the International Classification of Diseases code book. Those HCC patients who presented with spontaneous rupture of unresectable HCC were studied and analyzed. However, patients with hemorrhagic ascites without $\mathrm{HCC}$ or where the required information was incomplete were excluded.

The information about patient's demographics, etiology of underlying cirrhosis, clinical, radiological characteristics, laboratory parameters, stage of HCC, treatment provided and follow up in days were recorded. Child-Pugh score and Model for End Stage Liver Disease (MELD) score were used to define the severity of liver disease.

The main outcome measure was control of bleeding. The other outcome measures were in-hospital mortality, 30-day mortality, overall duration of survival and factors associated with 30-day mortality.

\section{Diagnosis and staging of ruptured of HCC and cirrhosis}

The diagnosis of HCC was made by combination of elevated alfa fetoprotein (AFP) (> $20 \mathrm{ng} / \mathrm{mL}$ ) and characteristic features of HCC on triple-phase computerized tomography (CT) scan/magnetic resonance imaging (MRI); or in the absence of elevated AFP when the concurrent results were found on CT scan/MRI along with presence of background chronic liver disease, with or without histological verification. The diagnosis of cirrhosis was made either on liver biopsy or in the absence of liver biopsy by clinical and laboratory features of portal hypertension i.e. varices on upper gastrointestinal endoscopy, radiological features suggestive of cirrhosis including irregular liver margins, dilated portal vein, spleenomegaly and ascites. ${ }^{[16]}$

"Spontaneous HCC rupture" was defined when it happened without a history of recent procedure or trauma and the "diagnosis" was established by using contrast CT of the abdomen. 
Modality of ruptured HCC diagnosis was defined as: (1) incidental when an asymptomatic HCC was discovered on imaging done during diagnostic procedures performed for some other disease; or (2) symptomatic when diagnosed during workup after symptom appearance. The HCC was considered as "non-advanced" if the lesion was solitary $\leq 5 \mathrm{~cm}$ or paucifocal $\leq 3$ lesions, with the largest diameter $\leq$ $3 \mathrm{~cm}$, in the absence of vascular invasion and distant metastases or "advanced," when the tumor exceeded these limits. Moreover, the HCC was also classified for macroscopic types as: (1) solitary; (2) paucifocal ( $\leq$ 3 nodules); (3) multifocal (> 3 nodules); (4) infiltrative (infiltrating pattern of $\mathrm{HCC}$ ); or (5) massive (huge mass with a diameter of $>10 \mathrm{~cm}$ and an undefined boundaries). ${ }^{[17]}$ In the presence of $\geq 2$ lesions, the largest tumor was considered as representative of $\mathrm{HCC}$ and the diameter of the representative tumor measured in its greatest dimension was recorded as tumor size. Furthermore, information was recorded regarding hepatic lobes involved, presence of portal vein thrombosis and extra hepatic spread.

The patients were treated "conservatively" when liver reserves were poor defined by a Child class $C$ or they were severely ill due to other comorbid conditions. TAE was performed in a well-equipped interventional radiological suite by a team of experienced interventional radiologists and Gel foam was used as embolizing agent. The study was conducted by maintaining compliance with the Helsinki Declaration and was approved by the Ethical review committee of Aga Khan University Hospital, Karachi.

\section{Statistical analysis}

Data was entered and analyzed in SPSS version 17.0. Mean $\pm S D$ and ranges were calculated for continuous variables and proportions for categorical variables. To see the difference between two groups independent student $t$-test, Chi square or Fisher exact was used where appropriate. A univariate logistic regression analysis was conducted to assess the (crude) association of the prognostic factors for 30day mortality. Biological significance and a value of $P$ $\leq 0.1$ were considered as criteria for a variable to be significant at univariate analysis. Biological plausible interactions among variables and confounding were also checked. Multivariable logistic regression was done and results are expressed as odds ratio (OR), along with $95 \%$ confidence interval $(\mathrm{Cl})$.

\section{RESULTS}

Clinical characteristics of patients

The medical records of 850 patients with HCC who had visited our center during the study period were reviewed. A total of 24 patients were diagnosed to have spontaneously ruptured, unresectable HCC and were analyzed. The mean age was $58.29 \pm$ 15.25 years (range 17-93 years) and most of them $21(87.5 \%)$ were males. Hepatitis $C$ was the most common cause of cirrhosis $(79.2 \%$ cases). The mean Child-Pugh score was $9.96 \pm 2.85$ (range 7-15) and mean MELD score was $17.92 \pm 6.38$ (range 9-32). On presentation $62.5 \%$ had decompensated cirrhosis and many of them had prior history of hospitalization with spontaneous bacterial peritonitis (16.7\%), portosystemic encephalopathy $(20.8 \%)$, variceal bleed $(12.5 \%)$ or hepatorenal syndrome $(4.2 \%)$. The most common clinical manifestations of ruptured HCC on presentation were sudden abdominal pain $(83.3 \%)$, hemoperitoneum $(54.2 \%)$, symptoms of anemia $(83.3 \%)$ and hypovolemic shock (25.0\%). Diagnosis of ruptured HCC was confirmed on CT scan of abdomen in all cases. The mean tumor size was 7.76 $\pm 4.22 \mathrm{~cm}$ (range $1.7-17.7 \mathrm{~cm}$ ). Almost two-third of patients had multifocal $(50.0 \%)$ or massive/infiltrative (25.0\%) HCC. Moreover, advanced HCC was found in $87.5 \%$ cases on presentation [Table 1].

A total of $11(45.8 \%)$ patients were treated conservatively who either had poor general condition, impaired hepatic reserves, multiple lesions, or when patient had declined any intervention. TAE was performed in 13 (54.8\%) cases of ruptured HCC. None of them underwent for emergency resection.

\section{Comparison of patients treated \\ conservatively vs. those treated with TAE}

There was no statistically significant difference in age, gender, etiology of underlying cirrhosis or symptoms and signs at presentation among those treated conservatively as compared to those who underwent TAE. The tumor size, macroscopic types, location and stage of HCC were also comparable among both groups [Table 2]. Although the prior hepatic decompensations, MELD and Child score were comparable in both groups, most of the patients in conservative group had patients with Child class $\mathrm{C}$ as compared to TAE group (54.5\% vs. $15.4 \%, P=0.08)$. Likewise, serum total bilirubin level $(5.14 \pm 3.50$ vs. 2.15 $\pm 1.04, P=0.008$ ) was higher and albumin was lower (2.04 \pm 0.41 vs. $2.63 \pm 0.49, P=0.004)$ in conservative treatment group as compared to TAE group.

The control of HCC bleeding was achieved in $66.7 \%$ cases which was significantly higher for those who were treated via TAE as compared to those who were treated conservatively $(92.3 \%$ vs. $36.4 \%, P=$ 0.008 ). Overall median duration for which the patients remained alive after $\mathrm{HCC}$ rupture was longer for 
Table 1: Demographic and clinic-pathological characteristics of all HCC patients at baseline $(n=24)$

\begin{tabular}{|c|c|}
\hline Characteristics & Data, mean \pm SD or $n(\%)$ \\
\hline Age (years) & $58.29 \pm 15.26$ (range 17-93) \\
\hline \multicolumn{2}{|l|}{ Etiology of CLD } \\
\hline $\mathrm{HCV}$ & $19(79.2)$ \\
\hline HBV & $3(12.5)$ \\
\hline NBNC & $2(8.3)$ \\
\hline \multicolumn{2}{|l|}{ Child class } \\
\hline A & $0(0)$ \\
\hline B & $16(66.7)$ \\
\hline C & $8(33.3)$ \\
\hline \multicolumn{2}{|l|}{ Abdominal pain } \\
\hline Yes & 20 (83.3) \\
\hline No & $4(16.7)$ \\
\hline \multicolumn{2}{|l|}{ Abdominal distension } \\
\hline Yes & $16(66.7)$ \\
\hline No & 8 (33.3) \\
\hline \multicolumn{2}{|l|}{ Anemia } \\
\hline Yes & $20(83.3)$ \\
\hline No & $4(16.7)$ \\
\hline \multicolumn{2}{|l|}{ Hypovolemic shock } \\
\hline Yes & $6(25)$ \\
\hline No & $18(75)$ \\
\hline \multicolumn{2}{|l|}{ Hemoperitonium } \\
\hline Yes & $13(54.2)$ \\
\hline No & $11(45.8)$ \\
\hline Mean hemoglobin (g/dL) & $8.4 \pm 3.0$ \\
\hline Platelet count $\left(10^{9} / \mathrm{L}\right)$ & $202.58 \pm 176.50$ \\
\hline Total lecucocyte count $\left(10^{9} / \mathrm{L}\right)$ & $10.96 \pm 4.17$ \\
\hline Prothrombin time (s) & $17.38 \pm 5.64$ \\
\hline Mean creatinine (mg/dL) & $1.35 \pm 0.57$ \\
\hline Serum total bilirubin (mg/dL) & $3.52 \pm 2.87$ \\
\hline Alanine transaminase (IU/L) (median) & 50.00 (range 13-768) \\
\hline Alkaline phosphatase (IU/L) & $210.13 \pm 158.07$ \\
\hline Albumin $(\mathrm{g} / \mathrm{dL})$ & $2.36 \pm 0.54$ \\
\hline Tumor size (size of largest lesion in $\mathrm{cm}$ ) & $7.76 \pm 4.22(1.7-17.7)$ \\
\hline AFP (IU/mL) (median) & 52.00 (range 1.00-100000) \\
\hline \multicolumn{2}{|l|}{ Macroscopic types } \\
\hline Solitary & $3(12.5)$ \\
\hline Paucifocal ( $\leq 3$ nodules) & $3(12.5)$ \\
\hline Multifocal (> 3 nodules) & $12(50.0)$ \\
\hline $\begin{array}{l}\text { Massive (huge diameter }>10 \mathrm{~cm} \text {, } \\
\text { undefined boundaries)/infiltrative }\end{array}$ & $6(25.0)$ \\
\hline \multicolumn{2}{|l|}{ Hepatic lobes (location of rupture) } \\
\hline Right & $12(50.0)$ \\
\hline Left & $1(4.2)$ \\
\hline Both & $11(45.8)$ \\
\hline \multicolumn{2}{|l|}{ Stage of $\mathrm{HCC}$} \\
\hline Non-advanced & $3(12.5)$ \\
\hline Advanced & $21(87.5)$ \\
\hline \multicolumn{2}{|l|}{ PVT } \\
\hline Yes & $10(41.7)$ \\
\hline No & 14 (58.3) \\
\hline \multicolumn{2}{|l|}{ Extra hepatic spread } \\
\hline Yes & $9(37.5)$ \\
\hline No & $15(62.5)$ \\
\hline
\end{tabular}

HCC: hepatocellular carcinoma; CLD: chronic liver disease; HCV: hepatitis C virus; HBV: hepatitis B virus; NBNC: non-B, non-C; MELD: Model for End Stage Liver Disease; AFP: alfa fetoprotein; PVT: portal vein thrombosis

TAE group (39 days, interquartile range 88 days) as compared to conservatively treated group ( 5 days, interquartile range 10 days) $(P=0.03)$. In addition, in- hospital mortality was significantly lower in TAE group as compared to patients treated conservatively $(30.8 \%$ vs. $72.7 \%, P=0.04)$. Moreover, 30 -day mortality was also lower in patients treated with TAE $(38.5 \%$ vs. $90.9 \%, P=0.01$ ) [Table 3].

\section{Predicting factors for 30-day mortality}

To find out the predicting factors for 30-day mortality, biologically plausible variables were tested on univariate analysis [Table 4]. The only factors which were found significant on univariate and multivariate analysis were TAE to control HCC bleed and control of bleeding. Those who underwent TAE had lower risk of mortality than conservatively treated group (OR $0.25,95 \% \mathrm{Cl} 0.07-0.90, P=0.03$ ). Failure to control bleeding was associated with higher 30 -day mortality (OR 2.14, 95\% Cl 1.24-3.68, $P=0.009$ ).

\section{DISCUSSION}

In this study, we have evaluated the clinicopathological characteristics, treatment outcomes and survival of patients presenting with spontaneously ruptured $\mathrm{HCC}$ who were treated conservatively or with TAE. Success rate for control of bleeding via TAE was higher than with conservative treatment. Overall median duration of survival after HCC rupture was longer for patients treated with TAE. In-hospital and 30-day mortality were significantly lower in TAE group.

The reported prevalence of spontaneously ruptured HCC ranges $5-15 \% .{ }^{[18]}$ The exact mechanism and risk factors for spontaneous rupture are not well known. However, subcapsular localization, rapid growth with tumor necrosis, portal hypertension and regional increase of venous pressure due to tumor thrombi or direct invasion could be responsible for $\mathrm{HCC}$ rupture. ${ }^{[19]}$

Sudden abdominal pain, hemoperitoneum and hypovolemic shock have been reported as the typical clinical features of ruptured HCC. ${ }^{[6,9,20]}$ Moreover, hemoperitoneum ascertained by performing abdominal paracentesis has been considered a reliable test to confirm the diagnosis in up to $86 \%$ of clinically suspected HCC rupture. ${ }^{[21]}$ Consistent with the results of other studies most of our patients were male, presented with abdominal pain and distention, hemoperitoneum and shock.

Doppler ultrasound and CT are useful modalities for the diagnosis of HCC rupture. ${ }^{[22]}$ The CT scan demonstrate HCC rupture by showing the vascular tumor, extent of the bleed and by showing serial density changes with the age of the hematoma. ${ }^{[23,24]}$ Triphasic contrast enhanced CT scan was done for all 
Table 2: Comparison of baseline characteristics of patients treated conservatively vs. those treated with TAE

\begin{tabular}{|c|c|c|c|}
\hline Characteristics & $\begin{array}{l}\text { Conservative treatment, } \\
\text { mean } \pm \text { SD or } n(\%), n=11\end{array}$ & $\begin{array}{c}\text { TAE, } \\
\text { mean } \pm \mathrm{SD} \text { or } n(\%), n=13\end{array}$ & $P$ value \\
\hline Age (years) & $61.36 \pm 16.13$ & $55.69 \pm 14.60$ & 0.37 \\
\hline Gender & & & 0.45 \\
\hline Male & $9(81.8)$ & $12(92.3)$ & \\
\hline Female & $2(18.2)$ & $1(7.7)$ & \\
\hline Etiology of cirrhosis & & & 0.72 \\
\hline $\mathrm{HCV}$ & $8(72.7)$ & $11(84.6)$ & \\
\hline HBV & $2(18.2)$ & $1(7.7)$ & \\
\hline NBNC & $1(9.1)$ & $1(7.7)$ & \\
\hline Decompensated cirrhosis & $6(54.5)$ & $9(62.5)$ & 0.67 \\
\hline Prior history of SBP & $3(27.3)$ & $1(7.7)$ & 0.30 \\
\hline Prior history of PSE & $3(27.3)$ & $2(15.4)$ & 0.63 \\
\hline Prior history of variceal bleed & $2(18.2)$ & $1(7.7)$ & 0.57 \\
\hline Prior history of HRS & $0(0)$ & $1(7.7)$ & 1.0 \\
\hline Abdominal pain & $8(72.7)$ & $12(92.3)$ & 0.22 \\
\hline Anemia & $9(81.8)$ & $11(84.6)$ & 0.85 \\
\hline Hypovolemic shock & $2(18.2)$ & $4(30.8)$ & 0.64 \\
\hline Ascites & $10(90.9)$ & $9(69.2)$ & 0.32 \\
\hline Hemoperitonium & $7(63.6)$ & $6(46.2)$ & 0.39 \\
\hline Child class & & & 0.08 \\
\hline A & $0(0)$ & $0(0)$ & \\
\hline $\mathrm{B}$ & $5(45.5)$ & $11(84.6)$ & \\
\hline $\mathrm{C}$ & $6(54.5)$ & $2(15.4)$ & \\
\hline Child score & $11.0 \pm 2.90$ & $9.08 \pm 2.60$ & 0.105 \\
\hline MELD score & $19.27 \pm 7.17$ & $16.77 \pm 5.67$ & 0.361 \\
\hline Prothrombin time (s) & $19.83 \pm 5.50$ & $15.32 \pm 5.07$ & 0.51 \\
\hline Serum total bilirubin $(\mathrm{mg} / \mathrm{dL})$ & $5.14 \pm 3.50$ & $2.15 \pm 1.04$ & 0.008 \\
\hline Albumin $(\mathrm{g} / \mathrm{dL})$ & $2.04 \pm 0.41$ & $2.63 \pm 0.49$ & 0.004 \\
\hline AFP (IU/mL) & & & 0.99 \\
\hline$\leq 20$ & $4(36.4)$ & $5(38.5)$ & \\
\hline$>20$ & $7(63.6)$ & $8(61.5)$ & \\
\hline Tumor size $(\mathrm{cm})$ & $7.64 \pm 4.14$ & $7.88 \pm 4.45$ & 0.892 \\
\hline Macroscopic type & & & 0.84 \\
\hline Solitary & $2(18.2)$ & $1(7.7)$ & \\
\hline Paucifical & $1(9.1)$ & $2(15.4)$ & \\
\hline Multifocal & $5(45.5)$ & 7 (53.8) & \\
\hline Infiltrative & $3(27.3)$ & $3(23.1)$ & \\
\hline Stage of HCC & & & 0.99 \\
\hline Non-advanced & $1(9.1)$ & $2(15.4)$ & \\
\hline Advanced & $10(90.9)$ & $11(84.6)$ & \\
\hline Hepatic lobes (location of rupture) & & & 0.53 \\
\hline Right & $5(45.5)$ & $7(53.8)$ & \\
\hline Left & $0(0)$ & $1(7.7)$ & \\
\hline Both & $6(54.5)$ & $5(38.5)$ & \\
\hline PVT & & & 0.69 \\
\hline Yes & $4(36.4)$ & $6(46.2)$ & \\
\hline No & 7 (63.6) & $7(53.8)$ & \\
\hline Extra hepatic spread & & & 0.42 \\
\hline Yes & $3(27.3)$ & $6(46.2)$ & \\
\hline No & $8(72.7)$ & $7(53.8)$ & \\
\hline
\end{tabular}

TAE: transarterial embolization; SBP: spontaneous bacterial peritonitis; PSE: porto systemic encephalopathy; HRS: hepatorenal syndrome; HCV: hepatitis C virus; HBV: hepatitis B virus; NBNC: non-B, non-C; MELD: Model for End Stage Liver Disease; AFP: alfa fetoprotein; HCC: hepatocellular carcinoma; PVT: portal vein thrombosis

of our patients and was found very useful in our study to confirm $\mathrm{HCC}$ rupture in all cases.

For spontaneously ruptured HCC, emergency hepatic resection with hepatic artery ligation has been used as preferred method of treatment in past. However, the procedure was found to be associated with high mortality of $44-73 \%$. Moreover, it is technically difficult to perform in decompensated liver disease and in palliative setting for advance disease where it could be associated with high likelihood of peritoneal seeding and poor outcome after resection. ${ }^{[6,12,18,25]}$ The majority of our patients had advanced HCC, with large tumor size (mean diameter $7.76 \mathrm{~cm}$ ) and multifocal disease. Hence, none of our patients had emergency hepatic resection. 
Table 3: Comparison of outcome among patients treated conservatively vs. those treated with TAE

\begin{tabular}{|c|c|c|c|c|}
\hline Outcomes & Overall & $\begin{array}{l}\text { Conservative treatment, } \\
n(\%) \text { or median } \pm \text { range }\end{array}$ & $\begin{array}{c}\text { TAE, } \\
n(\%) \text { or median } \pm \text { range }\end{array}$ & $P$ value \\
\hline Control of bleeding & & & & 0.008 \\
\hline Yes & $16(66.7)$ & $4(36.4)$ & $12(92.3)$ & \\
\hline No & $8(33.3)$ & 7 (63.6) & $1(7.7)$ & \\
\hline In hospital mortality & & & & 0.04 \\
\hline No & $12(50.0)$ & $3(27.3)$ & $9(69.2)$ & \\
\hline Yes & $12(50.0)$ & $8(72.7)$ & $4(30.8)$ & \\
\hline 30-day mortality & & & & 0.01 \\
\hline No & $9(37.5)$ & $1(9.1)$ & $8(61.5)$ & \\
\hline Yes & $13(54.2)$ & $10(90.9)$ & $5(38.5)$ & \\
\hline Median survival (days) & 11.5 (interquartile range 53 days) & 5 (interquartile range 10 days) & 39 (interquartile range 87.5 days) & 0.03 \\
\hline
\end{tabular}

TAE: transarterial embolization

Table 4: Univariate analysis for predicting factors for 30-day mortality

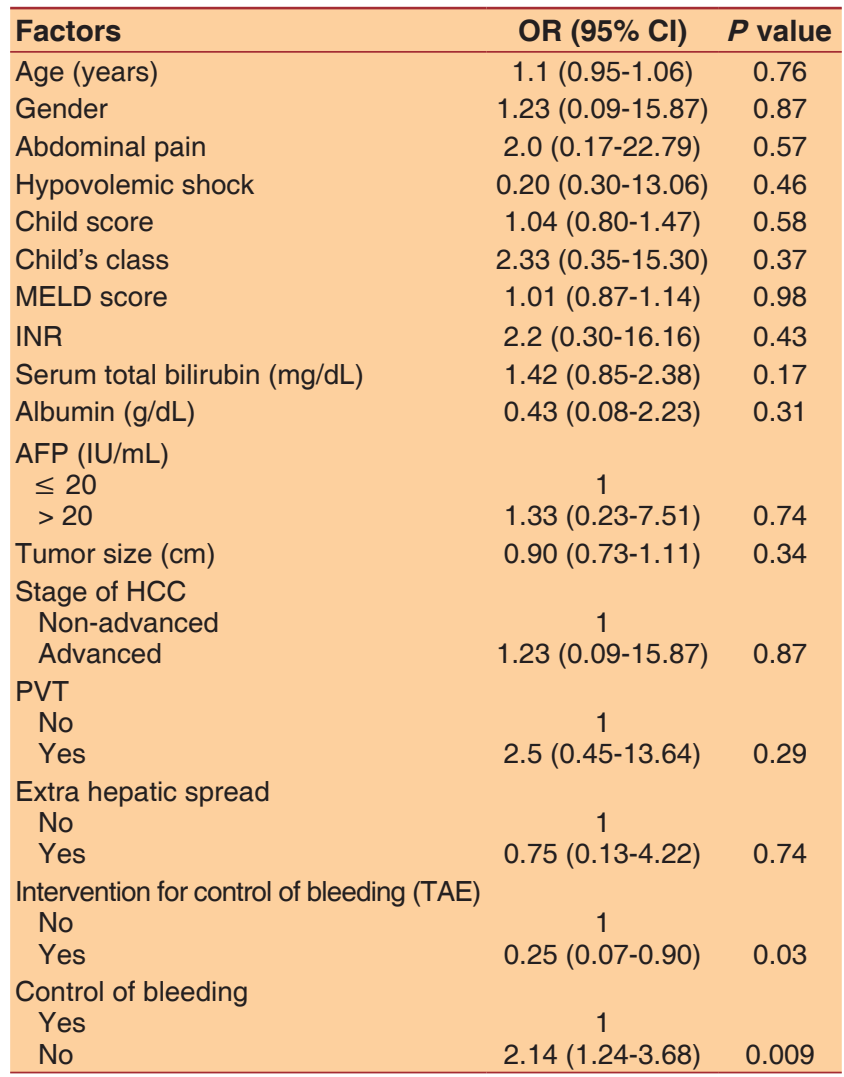

OR: odds ratio; $\mathrm{Cl}$ : confidence interval; MELD: Model for End Stage Liver Disease; INR: international normalized Ratio; AFP: alfa fetoprotein; HCC: hepatocellular carcinoma; PVT: portal vein thrombosis; TAE: transarterial embolization

TAE has been found to be associated with many complications including bleeding, post-embolization syndrome, implanted peritoneal metastases and mortality rate up to $30 \%$. However, considering TAE as minimally invasive and effective in achieving immediate hemostasis in patients with ruptured HCC as compared to resection, TAE could be a procedure of choice to achieve hemostasis without surgery for ruptured $\mathrm{HCC} .^{[26,27]}$ In the past it has been suggested that TAE should only be administered only in the presence of a patent portal vein. ${ }^{[28]}$ However, in our study we did not find any significant difference in the control of bleeding and 30-day mortality between patients having a patent or a thrombosed portal vein, its success in both conditions is comparable.

In a series of 62 patients with ruptured HCC, control of bleeding was achieved in $91 \%(57 / 62)$ cases after TAE. Moreover, 30 -day mortality was $38 \%$ and overall median survival time was 39 days. ${ }^{[2]}$ In another study, 3 out of 4 patients treated with TAE died within 30 days but most of them had Child's class $C$ cirrhosis. ${ }^{[30]}$ Likewise, TAE was found effective for control of bleeding in all 14 patients with $\mathrm{HCC}$ rupture, without significant impairment in liver function or treatment related deaths. However, only 3 patients survived for more than 6 months. ${ }^{[31]}$ A success rate of $83 \%$ has been reported in series from Hong Kong. ${ }^{\left[{ }^{[]}\right.}$Contrary to that conservative treatment has been reported to carry $100 \%$ mortality. ${ }^{[32]}$ Our results are consistent to the existing evidence. We found higher rates for control of bleeding after TAE as compared to conservative treatment $(92.3 \%$ vs. $36.4 \%$, $P=0.008$ ). In hospital mortality was $72.7 \%$ for those treated conservatively as compared to $30.8 \%$ after TAE. Moreover, our 30-day mortality rate was lower among our patients after TAE (38.5\%) as compared to what has been reported in previous studies. ${ }^{[6,9,33]}$ None of our patients had procedure related complications.

Severity of underlying cirrhosis, tumor size, vascular and extrahepatic spread, serum creatinine and hypovolemic shock have been reported as prognostic factors influencing survival after spontaneously ruptured HCC. ${ }^{[13,14,29,34]}$ Although majority of patients who underwent TAE had Child's class A or B and the conservative group had many patients with Child's class C; no significant difference was found in Child score or MELD score between the two groups. In our study, the only variables that were found to be associated with 30-day mortality were TAE and control of HCC bleed. This might be due to small sample size in our study. 
Our study had certain limitations; this is a retrospective, single-center study and our sample size was small. Moreover, none of our study patients had further locoregional therapy, or chemotherapy later on that could improve their life expectancy. However, considering ruptured HCC is an uncommon, life threatening complication, our study could provide some information about its manifestations and treatment options from this part of the world. The primary aim of managing patients with ruptured HCC is control of bleeding which could be an important factor in determining early mortality. Considering high success rate in control of bleeding, lower mortality rates and improvement in survival as well as quality of life, TAE could be used as procedure of choice to achieve hemostasis at presentation for ruptured HCC. Larger studies would be required to support currently available evidence in favor of TAE.

In conclusion, ruptured HCC is a life threatening complication requiring early diagnosis and treatment. TAE is an effective and well-tolerated treatment in the management of unresectable, ruptured HCC in patients with liver cirrhosis.

\section{Financial support and sponsorship None.}

\section{Conflicts of interest}

There are no conflicts of interest.

\section{Patient consent \\ Consent forms were obtained from the patients.}

\section{Ethics approval}

The study was conducted by maintaining compliance with the Helsinki Declaration and was approved by the Ethical review committee of Aga Khan University Hospital, Karachi.

\section{REFERENCES}

1. Altekruse SF, McGlynn KA, Reichman M. Hepatocellular carcinoma incidence, mortality, and survival trends in the United States from 1975 to 2005. J Clin Oncol 2009;27:1485-91.

2. Parkin DM, Bray F, Ferlay J, Pisani P. Global cancer statistics, 2002. CA Cancer J Clin 2005;55:74-108.

3. IARC. GLOBOCAN: Country Fast Stat 2008. Available from: http:// globocan.iarc.fr/Pages/fact_sheets_population.aspx. [cited August 22, 2016]

4. Butt AS, Hamid S, Wadalawala AA, Ghufran M, Javed AA, Farooq O, Ahmed B, Haq TU, Jafri W. Hepatocellular carcinoma in Native South Asian Pakistani population; trends, clinico-pathological characteristics $\&$ differences in viral marker negative \& viral-hepatocellular carcinoma. BMC Res Notes 2013;6:137

5. Abbasi A, Butt N, Bhutto AR, Gulzar K, Munir SM. Hepatocellular carcinoma: a clinicopathological study. J Coll Physicians Surg Pak 2010;20:510-3.

6. Ong GB, Chu EP, Yu FY, Lee TC. Spontaneous rupture of hepatocellular carcinoma. Br J Surg 1965;52:123-9.

7. Lai EC, Lau WY. Spontaneous rupture of hepatocellular carcinoma: a systematic review. Arch Surg 2006;141:191-8.

8. Hirai K, Kawazoe Y, Yamashita K, Kumagai M, Nagata K, Kawaguchi $\mathrm{S}$, Abe M, Tanikawa K. Transcatheter arterial embolization for spontaneous rupture of hepatocellular carcinoma. Am J Gastroenterol 1986;81:275-9.

9. Liu CL, Fan ST, Lo CM, Tso WK, Poon RT, Lam CM, Wong J. Management of spontaneous rupture of hepatocellular carcinoma: single-center experience. J Clin Oncol 2001;19:3725-32.

10. Aoki T, Kokudo N, Matsuyama Y, Izumi N, Ichida T, Kudo M, Ku Y, Sakamoto M, Nakashima O, Matsui O, Makuuchi M; Liver Cancer Study Group of Japan. Prognostic impact of spontaneous tumor rupture in patients with hepatocellular carcinoma: an analysis of 1160 cases from a nationwide survey. Ann Surg 2014;259:532-42.

11. Tan FL, Tan YM, Chung AY, Cheow PC, Chow PK, Ooi LL. Factors affecting early mortality in spontaneous rupture of hepatocellular carcinoma. ANZ J Surg 2006;76:448-52.

12. Leung KL, Lau WY, Lai PB, Yiu RY, Meng WC, Leow CK. Spontaneous rupture of hepatocellular carcinoma: conservative management and selective intervention. Arch Surg 1999;134:1103-7.

13. Kim JY, Lee JS, Oh DH, Yim YH, Lee HK. Transcatheter arteria chemoembolization confers survival benefit in patients with a spontaneously ruptured hepatocellular carcinoma. Eur J Gastroenterol Hepatol 2012;24:640-5.

14. Yeh CN, Lee WC, Jeng LB, Chen MF, Yu MC. Spontaneous tumour rupture and prognosis in patients with hepatocellular carcinoma. $\mathrm{Br} J$ Surg 2002;89:1125-9.

15. Karachi the Gatway to Pakistan. Available from: http://www.kmc.gos. pk/Contents.aspx?id=14. [cited August 22, 2016]

16. Bruix J, Sherman M; American Association for the Study of Liver Diseases. Management of hepatocellular carcinoma: an update. Hepatology 2011;53:1020-2.

17. Trevisani F, De Notariis S, Rapaccini G, Farinati F, Benvegnù L, Zoli M, Grazi GL, Del PP, Di N, Bernardi M; Italian Liver Cancer Group. Semiannual and annual surveillance of cirrhotic patients for hepatocellular carcinoma: effects on cancer stage and patient survival (Italian experience). Am J Gastroenterol 2002;97:734-44.

18. Vergara V, Muratore A, Bouzari H, Polastri R, Ferrero A, Galatola G, Capussotti L. Spontaneous rupture of hepatocelluar carcinoma: surgical resection and long-term survival. Eur J Surg Oncol 2000;26:770-2.

19. Akriviadis EA. Hemoperitoneum in patients with ascites. Am J Gastroenterol 1997;92:567-75

20. Tanaka A, Takeda R, Mukaihara S, Hayakawa K, Shibata T, Itoh K, Nishida N, Nakao K, Fukuda Y, Chiba T, Yamaoka Y. Treatment of ruptured hepatocellular carcinoma. Int J Clin Oncol 2001;6:291-5.

21. Miyamoto M, Sudo T, Kuyama T. Spontaneous rupture of hepatocellular carcinoma: a review of 172 Japanese cases. Am J Gastroenterol 1991;86:67-71.

22. Choi JH, Kim JH, Won JH, Kim YS, Goo DE, Choi DL. Spontaneous intratumoral hemorrhage into hepatocellular carcinoma during transcatheter arterial embolization: a case report. J Korean Med Sci 2004; 19:895-7.

23. Choi BG, Park SH, Byun JY, Jung SE, Choi KH, Han J. The findings of ruptured hepatocellular carcinoma on helical CT. Br J Radiol 2001;74:142-6.

24. Lubner M, Menias C, Rucker C, Bhalla S, Peterson CM, Wang L, Gratz B. Blood in the belly: CT findings of hemoperitoneum. Radiographics 2007;27:109-25.

25. Leung CS, Tang CN, Fung KH, Li MK. A retrospective review of transcatheter hepatic arterial embolisation for ruptured hepatocellular carcinoma. J R Coll Surg Edinb 2002;47:685-8.

26. Shimada R, Imamura H, Makuuchi M, Soeda J, Kobayashi A, Noike 
T, Miyagawa S, Kawasaki S. Staged hepatectomy after emergency transcatheter arterial embolization for ruptured for ruptured hepatocellular carcinoma. Surgery 1998;124:526-35.

27. Hai L, Yong-Hong P, Yong F, Ren-Feng L. One-stage liver resection for spontaneous rupture of hepatocellular carcinoma. World J Surg 2005;29:1316-8

28. Jin YJ, Lee JW, Park SW, Lee JI, Lee DH, Kim YS, Cho SG, Jeon YS, Lee KY, Ahn SI. Survival outcome of patients with spontaneously ruptured hepatocellular carcinoma treated surgically or by transarterial embolization. World J Gastroenterol 2013;19:4537-44.

29. Li WH, Cheuk EC, Kowk PC, Cheung MT. Survival after transarterial embolization for spontaneous ruptured hepatocellular carcinoma. $J$ Hepatobiliary Pancreat Surg 2009;16:508-12.

30. Bassi N, Caratozzolo E, Bonariol L, Ruffolo C, Bridda A, Padoan L, Antoniutti M, Massani M. Management of ruptured hepatocellular carcinoma: implications for therapy. World J Gastroenterol 2010;16:1221-5.
31. Castells L, Moreiras M, Quiroga S, Alvarez-Castells A, Segarra A, Esteban R, Guardia J. Hemoperitoneum as a first manifestation of hepatocellular carcinoma in western patients with liver cirrhosis: effectiveness of emergency treatment with transcatheter arterial embolization. Dig Dis Sci 2001;46:555-62.

32. Chearanai O, Plengvanit U, Asavanich C, Damrongsak D, Sindhvananda K, Boonyapisit S. Spontaneous rupture of primary hepatoma: report of 63 cases with particular reference to the pathogenesis and rationale treatment by hepatic artery ligation. Cancer 1983;51:1532-6.

33. Battula N, Madanur M, Priest O, Srinivasan P, O’Grady J, Heneghan MA, Bowles M, Muiesan P, Heaton N, Rela M. Spontaneous rupture of hepatocellular carcinoma: a Western experience. Am J Surg 2009;197:164-7.

34. Shin BS, Park MH, Jeon GS. Outcome and prognostic factors of spontaneous ruptured hepatocellular carcinoma treated with transarterial embolization. Acta Radiol 2011;52:331-5. 